\title{
CORRECTION FOR THE CIRRUS CLOUD TOP HEIGHT OF MODIS BASED ON CALIPSO IN BEIJING-TIANJIN-HEBEI REGION
}

\author{
Bingyun Yang, Jian Liu*, Xu Jia \\ National Satellite Meteorological Center, Beijing 100081, China (yangby, liujian, jiax@cma.gov.cn)
}

Commission III, WG III/8

KEY WORDS: Cirrus, Cloud Top Height, Correction, MODIS, CALIPSO

\begin{abstract}
:
Cirrus plays an important role in atmospheric radiation. It affects weather system and climate change. Satellite remote sensing is an important kind of observation for cloud. As a passive remote sensing instrument, large bias was found for thin cirrus cloud top height retrieval from MODIS (Moderate Resolution Imaging Spectroradiometer). Comparatively, CALIOP (Cloud-Aerosol Lidar with Orthogonal Polarization) aboard CALIPSO (Cloud-Aerosol Lidar and Infrared Pathfinder Satellite Observation) which is an active remote sensing instrument can acquire more accurate characteristics of thin cirrus cloud. In this study, CALIPSO cirrus cloud top height data was used to correct MODIS cirrus cloud top height. The data analysis area was selected in Beijing-Tianjin-Hebei region and data came from 2013 to 2017. Linear fitting method was selected based on cross-validation method between MODIS and CALIPSO data. The results shows that the difference between MODIS and CALIPSO changes from $-3 \sim 2 \mathrm{~km}$ to $-2.0 \sim 2.5 \mathrm{~km}$, and the maximum difference changes from about $-0.8 \mathrm{~km}$ to about $0.2 \mathrm{~km}$. In the context of different vertical levels and cloud optical depth, MODIS cirrus cloud top height is improved after correcting, which is more obvious at lower cloud top height and optical thinner cirrus.
\end{abstract}

\section{INTRODUCTION}

Cirrus is a kind of high-level cloud which is located in the middle to upper troposphere and the lower stratosphere. It plays an important role in atmospheric radiation. Cirrus can not only reduce the energy reaching the surface and atmosphere by reflecting solar radiation, but also absorb the long-wave radiation emitted by the surface and atmosphere to heat the atmosphere. Thus, it affects the balance of global energy budget, the weather system and climate change (Liou, 1986). The detection of cirrus is a hot and difficult problem in the field of atmospheric science.

Cirrus can be observed by many ways, such as artificial visual observation, ground-based instrument observation, sounding observation and satellite remote sensing observation. The macroscopic parameters (such as cloud amount, cloud height, cloud top temperature) and microphysical parameters (e.g., optical thickness and particle size) can be obtained from these ways. Artificial visual observation is a traditional way to estimate the base height of cirrus by judging cloud type information through human experience. However, cirrus is usually very thin and sometimes cannot be recognized by human eyes. Vertical detections of ground-based remote sensing, including laser cloud altimeters, thermal infrared imagers and millimeter-wave radars, have the advantage of time continuity. The location of cloud can be detected by the received echo signal, and then the vertical detection of cloud can be realized (Lu et al., 2012; Hu et al., 2012; Wang et al., 2016). However, the coverage of ground-based observation is small, and the echo signal is attenuated by the influence of low and middle level clouds, which leads to the deviation in detected high cloud top height (Zhou et al., 2010; Cao et al., 2015). Satellite remote sensing observation has a good spatial coverage and better spatial-temporal resolution. The retrieval of cirrus by satellite has a history of more than ten years. Not only the height of cirrus, but also the microphysical characteristics of cirrus such as optical thickness and effective radius, can be retrieved (King, 1987; Nakajima and King, 1990; Planick el al., 2003). The passive visible infrared radiometer (such as MODIS (Moderate Resolution Imaging Spectroradiometer) on Terra and Aqua polar orbiting satellites) mainly receives echo from cloud top. When the cirrus is thin, the surface radiation can penetrate the cloud to the satellite sensor. The satellite receives the cloud top radiation and surface radiation at the same time, and the cirrus retrieval top height is biased consequently (Sassen and Campbell, 2001). As active remote sensing detectors, CPR (Cloud Profile Radar) onboard CloudSat and CALIOP (CloudAerosol Lidar with Orthogonal Polarization) onboard CALIPSO have great abilities of vertical detection (Stephens et al., 2002; Wang and Sassen, 2002). They can emit radiation which can penetrate into the interior of clouds and obtain vertical structure information, e.g., cloud top and cloud bottom height (Nazaryan et al., 2008; Haladay et al., 2009; Heidinger et al., 2010; Thorsen et al., 2011; Zhang et al., 2015; Yang et al., 2014, 2017, 2018). Because CALIPSO-CALIOP is more sensitive to thin cloud and more accurate in estimating the height of cirrus cloud top (Weisz et al., 2007), it is usually used as a kind of validation data for passive remote sensing products. Holz et al. (2008) pointed out that MODIS underestimated the cloud top height of thin optical clouds when the cloud top height was greater than 5 $\mathrm{km}$, based on CALIOP. Menzel et al. (2013) used CALIOP data to evaluate MODIS MOD06 products and found a significant negative bias of cloud top height between MOD06 and CALIOP, especially for cirrus.

Aqua and CALIPO are on the A-Train series orbit and their observation time is close, but the detection coverage is quite

\footnotetext{
* Corresponding author
} 
different. As shown in Figure 1, CALIOP has a narrow clipping range and linear distribution on MODIS images.

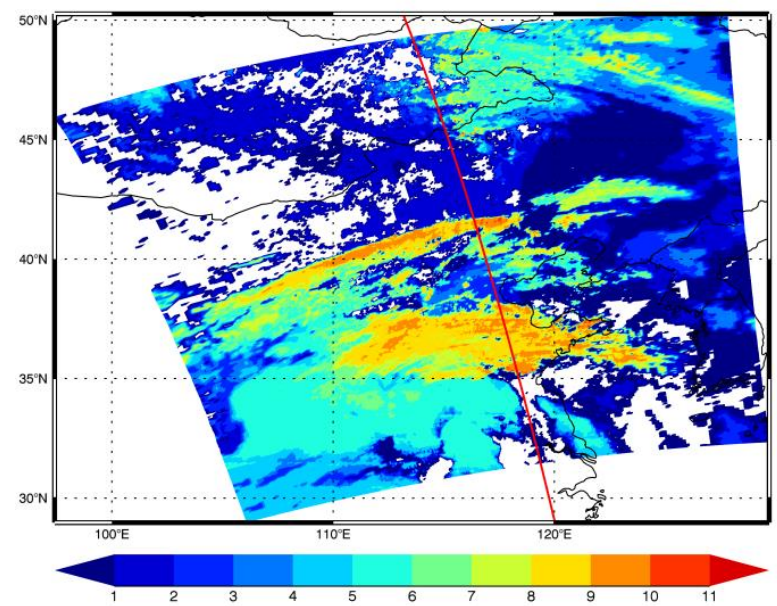

Figure 1. Image of cloud top height from MODIS at 05:25, Jan 1,2017

(unit: $\mathrm{km}$; red line is the orbit of CALIPSO)

CALIPO has high detection capability for cirrus, but its observation space range is narrow. Aqua/MODIS covers a wide scope of observation space, but its detection accuracy for cloud top height, especially for thin cirrus, is not as good as that of CALIPSO. How to make better use of the advantage of high precision in CALIPSO cirrus detection to correct the MODIS cirrus cloud top height, in order to highlight the characteristics of MODIS detection in wide range, is a key research point. This paper is organized as follows: firstly, a brief introduction to Aqua/MODIS and CALIIPSO data, as well as the correction method based on CALIPSO for MODIS cirrus cloud top height, are given in section 2. The correction results are presented in section 3. At last, conclusion and discussion are in section 4 .

\section{MATERIALS AND METHODS}

\subsection{MODIS, CALIPSO}

A-Train series satellites are polar orbiting satellites launched by the United States independently in the same orbit, including OCO-2, GCOM-W1, CloudSat, CALIPSO, Aqua, Aura and etc. The Aqua satellite was launched on May 4, 2002, equipped with AMSR-E, MODIS, AMSU-A, AIRS, CERES and other sensors. Among them, MODIS is a medium-resolution imaging spectrometer containing 36 spectral bands with spectrum ranging from $0.4 \mu \mathrm{m}$ to $14.4 \mu \mathrm{m}$. The radiation information of cloud, aerosol, atmosphere and surface can be obtained from these bands (Barnes el al., 2003). MODIS cloud top products are derived using $\mathrm{CO}_{2}$ slice method based on five infrared channels, under the assumption of single layer clouds (Menzel el al., 2008). After accessing to the cloud top pressure, the cloud top height and cloud top temperature are transformed from NECP Global Forecast System (GFS). The height of thin cirrus clouds is generally underestimated due to the use of infrared channel for cloud top height retrieval (Menzel el al., 2013). In this paper, Aqua MODIS L2 version 6.0 cloud product (MYD06) is used. Its spatial resolution is $1 \mathrm{~km}$.

CALIPSO satellite was launched on April 28, 2006, equipped with sensors such as CALIOP, WFC and IIR. CALIOP is a dual-wavelength sensitive polarization lidar, which can detect profiles of clouds and aerosols with high vertical resolution, and is thus more sensitive to cirrus detection (Winker el al., 2004, 2007, 2009; Hagihara el al., 2014).

CALIPSO satellite level-2 cloud layer product CAL_LID_L2_01 kmCLay-Standard-V4-10 is used in this paper, which has a horizontal resolution of $1 \mathrm{~km}$. The data mainly includes the parameters, such as the cloud top and bottom height, cloud temperature, cloud pressure, reflectivity and backscattering (Vaughan el al., 2004). Cloud and aerosol are identified by adjusting the threshold of backscattering of laser radar at 532 and $1064 \mathrm{~nm}$ wavelengths.

In this study, MODIS and CALIPSO data is selected during 2013-2017.

\subsection{Cirrus Detection}

For MODIS data, cirrus is detected according to ISCCP cloud classification criteria (Rossow and Schiffer, 1999; Cho el al., 2008): i.e., cloud optical thickness is between 0 and 3.6, and cloud top pressure is between 50 and $440 \mathrm{hPa}$. Cirrus for CALIPSO is recognized by the criteria proposed by Meenu et al. (2011): (1) according to Feature_Classification_Flags, the feature type is cloud and the subtype is cirrus; (2) CAD (Cloud Aerosol Discrimination) score is between 80 and 100; (3) FFQC (Feature Finder Quality Control) value is 0 . The latter two criteria indicate high reliability in the feature recognition.

\subsection{Matching Method between MODIS and CALIPSO Data}

In the constellation of A-train series, there is a lag of 3 minutes in CALIPSO observation relative to Aqua, and the difference between them is negligible. The scanning width of MODIS data orbit is $2330 \mathrm{~km}$, and the horizontal resolution of CALIPSO sub-satellite point is $330 \mathrm{~m}$. According to the principle of nearest point matching, MODIS pixels are selected corresponding to the longitude and latitude of CALIPSO scanning points.

\subsection{Correction Method of Cirrus Cloud Top Height}

There are total 5 years matched data from 2013 to 2017. Four years data were used as training data for modeling, and one year was used as testing data for validation. Linear regression and cross-validation were used to analysis the relationship between cloud top heights of MODIS and CALIPSO, and a correction model was established. In detail, rolling cycle method was implemented, that was, 4 years data of 2013-2017 were modeled and 1 other year data was tested. This cycling method was processed to ensure that each year can be used as test data. Thus, five fitting coefficients and corresponding correction errors were quantified respectively. Figure $2 \mathrm{a} \sim \mathrm{e}$ show the fitting results of MODIS and CALIPO cirrus cloud top height with the test data of 2013, 2014, 2015, 2016 and 2017 respectively. The fitting parameters are shown in Table 1. It is clear that the five sets are fitted in linear distribution. Each regression model can pass the 0.01 confidence test. 

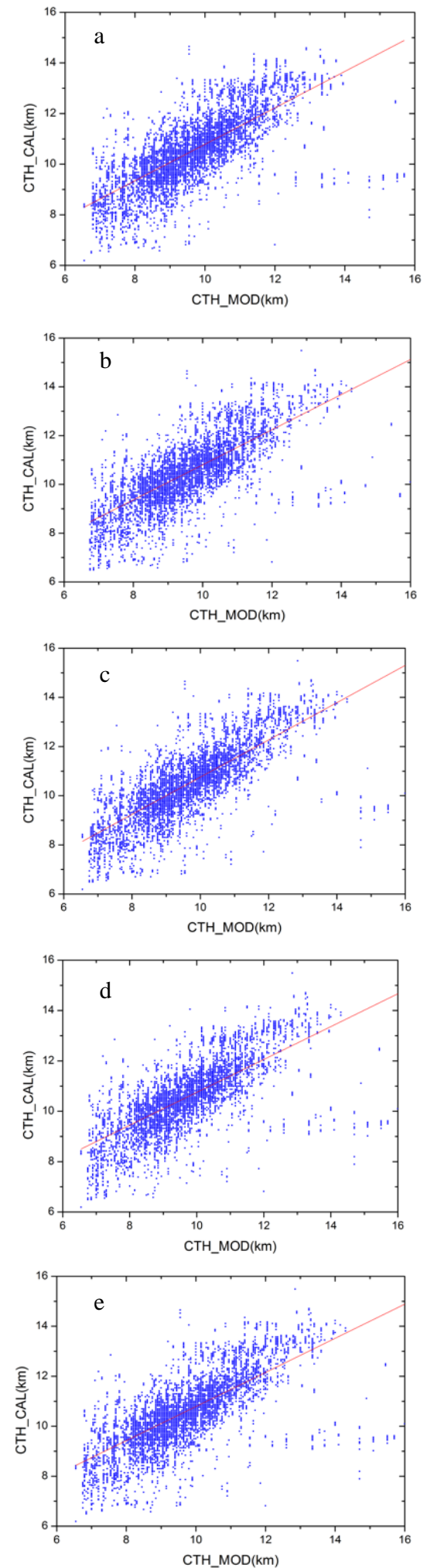

Figure 2. Linear fitting and probability distribution of cloud top height

( $\mathrm{x}$ and $\mathrm{y}$ axis in the five panels above represent cloud top height of MODIS and CALIPSO, with unit of $\mathrm{km}$. The panels from top to bottom represent fitting results from every four years out of 2013-2017)

\begin{tabular}{ccccccc}
\hline $\begin{array}{r}\text { Test } \\
\text { data }\end{array}$ & $\begin{array}{c}\text { Sample } \\
\text { number }\end{array}$ & Linear fitting equation & $\mathrm{R}^{2}$ & RMSE & $\begin{array}{c}\mathrm{R} \\
\text { RMSE }\end{array}$ \\
\hline 2013 & 1343 & $y=0.720 x+3.584$ & 0.546 & 1.062 & 0.101 \\
2014 & 1713 & $y=0.720 x+3.606$ & 0.397 & 1.051 & 0.099 \\
2015 & 2454 & $y=0.757 x+3.184$ & 0.444 & 0.924 & 0.088 \\
2016 & 2414 & $y=0.652 x+4.231$ & 0.360 & 0.930 & 0.088 \\
2017 & 1984 & $y=0.683 x+3.960$ & 0.384 & 0.796 & 0.077 \\
\hline
\end{tabular}

Table 1. Parameter of linear fitting cloud top height between MODIS and CALIPSO for different training dataset

For five sets of fitting results, the difference of fitting coefficients is little. It indicates there is weak interannual variation among these data. According to Table 1, the final correction model with the data of 2017 as the test data and the data of 2013-2016 as the fitting data has the smallest validated error, which is chosen as the corrected model.

\section{RESULTS}

\subsection{Correction of Cirrus Cloud Top Height}

Figure 3 is the correction result of the cirrus cloud top height based on MODIS data in 2017. From the scatter plot of raw MODIS, corrected MODIS and CALIPSO (Figure 3a), they show a similar distribution pattern. The cloud top height is mainly located between 6 and $15 \mathrm{~km}$, and the peak height is about $9 \mathrm{~km}$. There are two peaks in the distribution of CALIPSO cloud top height, i.e., near $10 \mathrm{~km}$ and $11.5 \mathrm{~km}$. After correction (Figure 3b), the peak height of MODIS cloud top is around $11 \mathrm{~km}$, which is closer to the probability distribution curve of CALIPSO. The most concentrated distribution range is $10 \sim 11 \mathrm{~km}$. Meanwhile, the number of detection data below 9 $\mathrm{km}$ is less, and there is a bias compared with CALIPSO.

The difference between cloud top height of raw MODIS and CALIPSO is mostly less than $0 \mathrm{~km}$, that means MODIS cloud height is lower than CALIPSO (Figure 3c). After correction, the difference between MODIS and CALIPSO became smaller. Figure $3 \mathrm{~d}$ is a diagram of the probability distribution function. It can be seen that the difference between MODIS raw data and CALIPSO is about -3 and $2 \mathrm{~km}$ and the highest frequency appeared near $-0.8 \mathrm{~km}$. After correction the difference between corrected MODIS and CALIPSO is $-2.0 \sim 2.5 \mathrm{~km}$, with the highest frequency being near $0.2 \mathrm{~km}$.

In order to discuss the performance of correction for cirrus at different height, the cloud top height is divided to different ranges, i.e., lower than $8 \mathrm{~km}, 8 \sim 9 \mathrm{~km}, 9 \sim 10 \mathrm{~km}, 10 \sim 11 \mathrm{~km}$, $11 \sim 12 \mathrm{~km}$ and higher than $12 \mathrm{~km}$, as demonstrated in Figure 4 . It is clear that corrected MODIS and CALIPSO have the similar distribution pattern, and the highest frequency of difference between them is about $-1 \sim 1 \mathrm{~km}$. It suggests that the performance of correction is generally obvious for different heights. The correction effect varies with cloud top height. The lower cloud top height, the better the correction is, especially for cloud top height lower than $8 \mathrm{~km}$.

Secondly, the correction effect of cirrus clouds with different optical thickness is researched. The optical thickness of cirrus for MODIS is divided into four ranges, i.e., 0 1.0, 1.0 2.0, 
2.0 3.0 and 3.0 3.6. It shows that corrections for different thickness are generally effective (Figure 5). The probability distribution of the difference between corrected MODIS and CALIPSO closes to unbiased distribution. As thickness increases, the difference between corrected MODIS and raw MODIS decreases. It shows that the correction method is more effective to cirrus with thinner optical thickness.
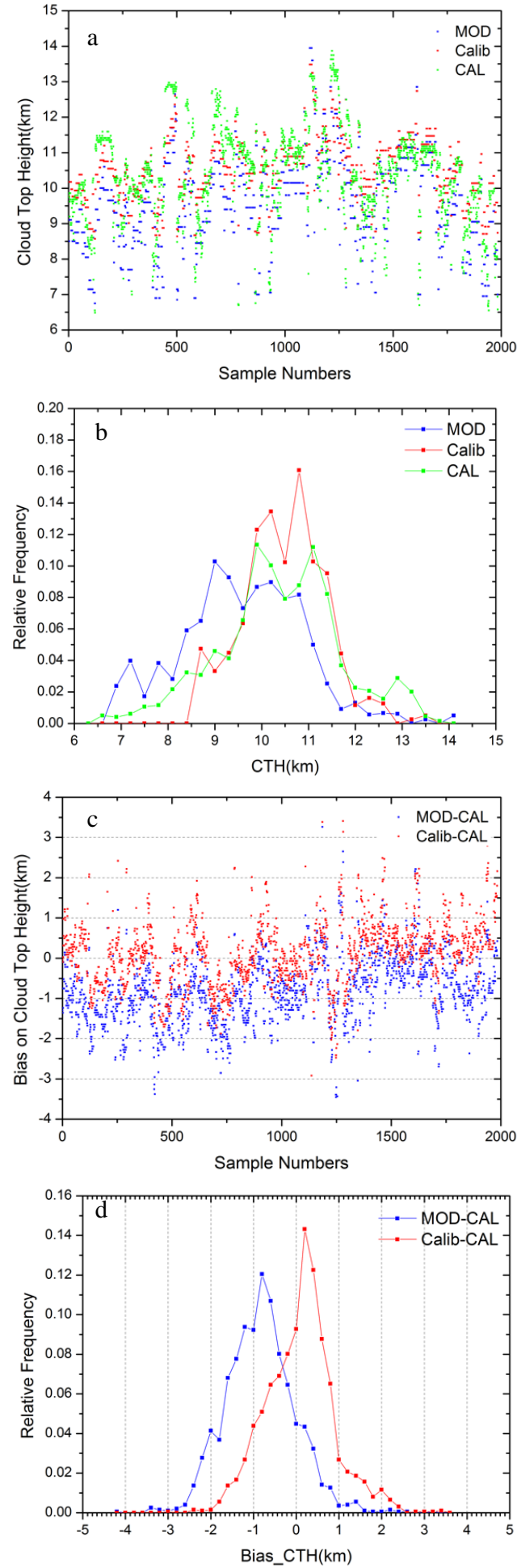

Figure 3. Correction for cloud top height in 2017 (a and $\mathrm{b}$ represent scatter distribution and probability distribution of cloud top height for raw MODIS (blue), corrected MODIS (red) and CALIPSO (green). $\mathrm{c}$ and d represent scatter distribution and probability distribution for the difference between height of raw MODIS and CALIPSO (blue), corrected MODIS and CALIPSO (red))
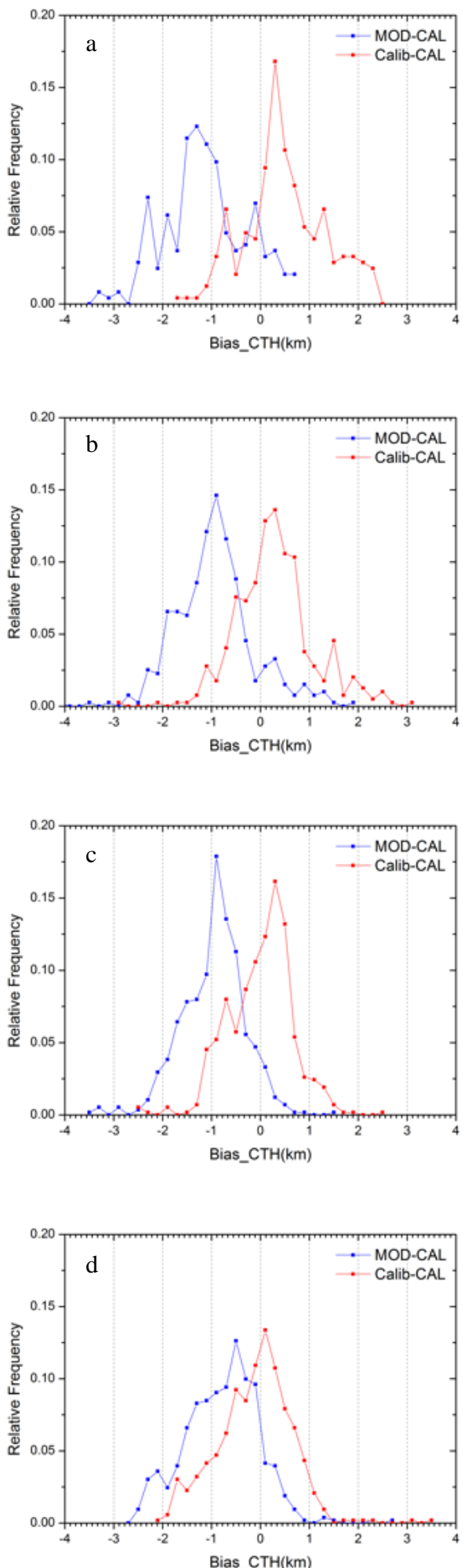

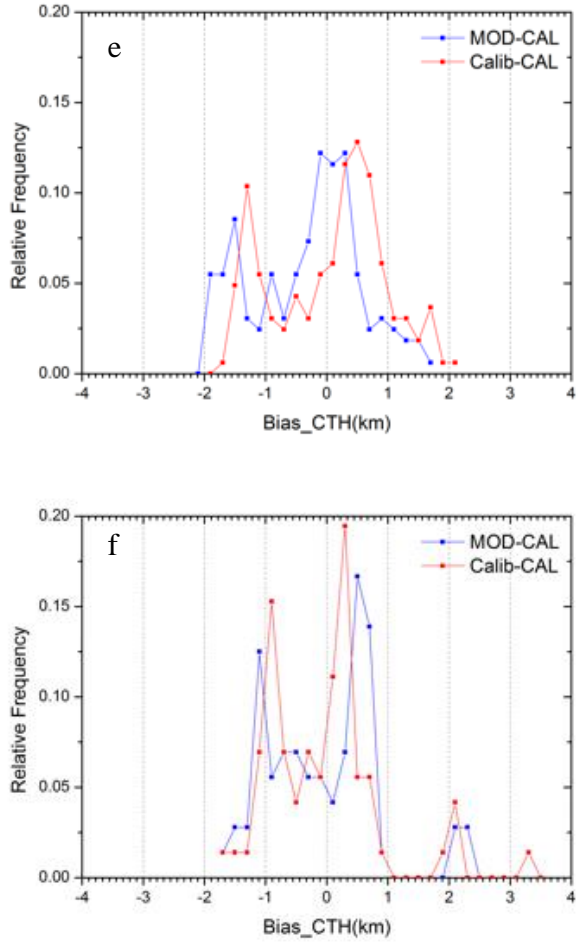

Figure 4. Comparison of correction for cloud top height of cirrus at different altitudes in 2017

(a, b, c, d, e and f represent the comparison at raw MODIS < 8 , 8-9, 9-10, 10-11, 11-12 and $>12 \mathrm{~km}$, respectively; blue and red line represent probability distribution for the difference between height of raw MODIS and CALIPSO, corrected MODIS and CALIPSO)
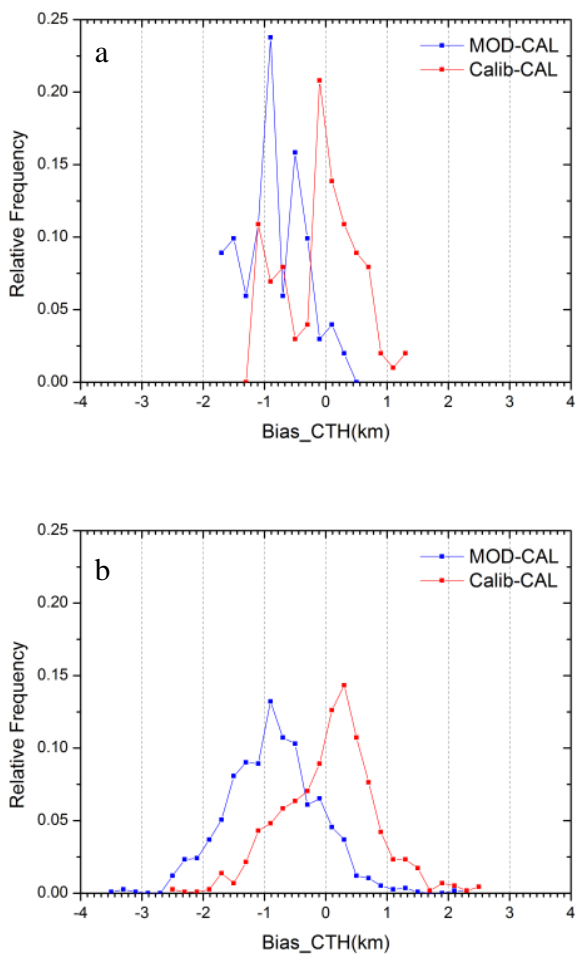
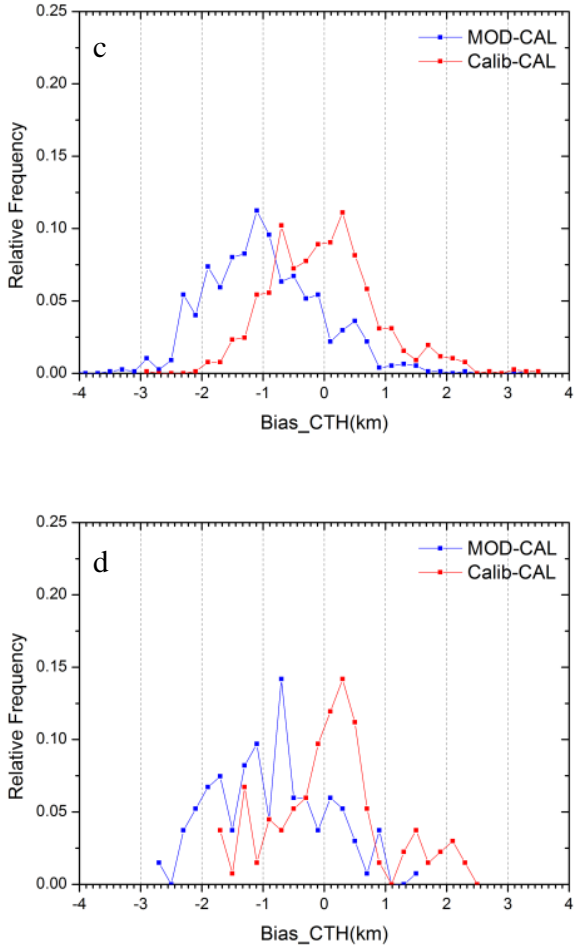

Figure 5. Comparison of correction for cloud top height of cirrus at different cloud optical depth in 2017

(a, b, c and d represent the comparison of the raw cloud optical depth at 0 1.0、1.0 2.0、2.0 3.0、3.0 3.6, respectively; blue and red line represent probability distribution for the difference

between height of raw MODIS and CALIPSO, corrected MODIS and CALIPSO)

\subsection{Cloud Top Height Annual Distribution before and after Revision}

The 2003-2017 MODIS cloud top height is corrected according to section 2.4. Annual mean cloud top height is calculated for before and after correction. The results are showed in Figure 6 . Figure 6a is the image of annual mean MODIS cloud top height before correction. Figure $6 \mathrm{~b}$ is the annual mean cloud top height after correction. Figure $6 \mathrm{c}$ is the difference between before and after correction. Higher cloud top height areas are found in central Hebei, Bohai Bay and eastern Shandong Peninsula, corresponding to smaller correction value.

The probability distribution of cloud top height before and after correction is showed in Figure 7. It can be seen that the corrected cloud top height increases from $9.35 \sim 10.30 \mathrm{~km}$ to $10.15 \sim 11.05 \mathrm{~km}$. The maximum frequency changes from 9.55 $\mathrm{km}$ (probability distribution is 0.113 ) to $10.5 \mathrm{~km}$ (probability distribution is 0.171 ). Moreover, the range of corrected cloud top height is smaller than raw cloud top height. The corrected change value is about $0.69 \sim 1.07 \mathrm{~km}$ and the highest frequency is near $0.91 \mathrm{~km}$. 


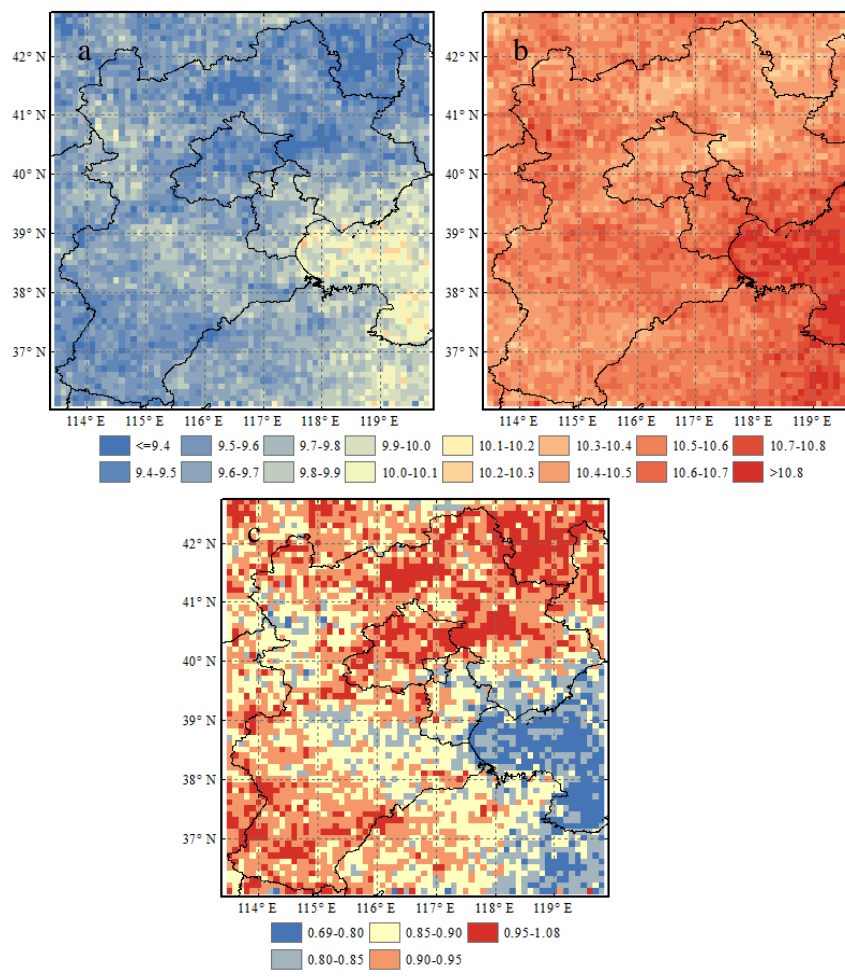

Figure 6. Distribution of raw and corrected cloud top height of cirrus during 2013-2017

(a, b and c represent raw height, corrected height, difference between corrected height and raw height, respectively)
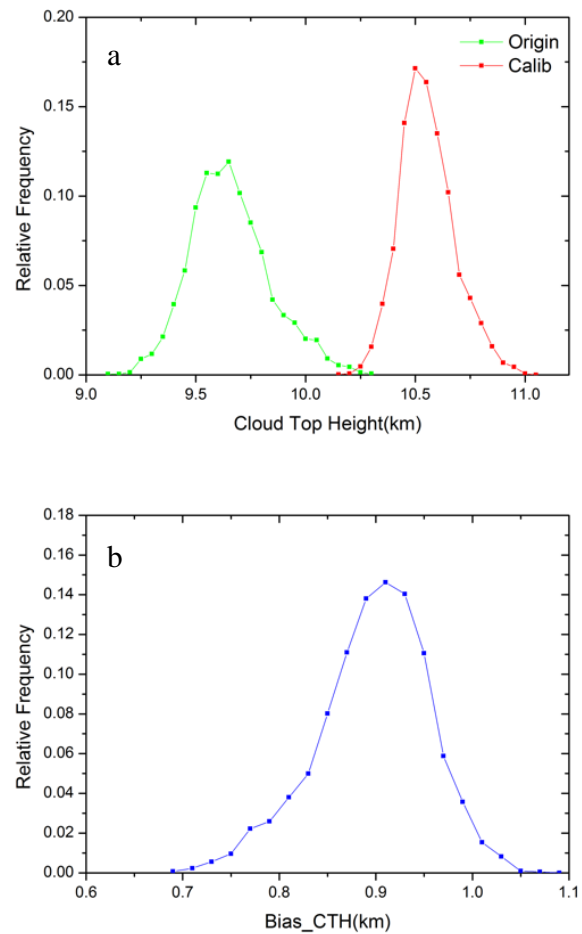

Figure 7. Probability distribution of raw and corrected cloud top height of cirrus during 2013-2017

(a represents raw height and corrected height, green and red line represent raw height and corrected height, respectively, b represents the difference between corrected height and raw height)

\section{CONCLUSION AND DISCUSSION}

Based on cloud top height data of MODIS and CALIPSO from 2013 to 2017 in Beijing-Tianjin-Hebei region, a linear fitting way was obtained by cross-validation method. All MODIS cloud top height data were processed using correction method. The main findings are as follows:

(1) The linear regression of cirrus cloud top height between MODIS and CALIPSO is well. The model arrives at the 0.01 significance level. The probability distribution demonstrates that the cloud top height of CALIPSO is higher than MODIS and the respective highest frequency is around $10 \sim 11 \mathrm{~km}$ (CALIPSO) and 9 10 km (MODIS).

(2) Cross-validation method is used to evaluate the correction results. After correction, the probability distribution of corrected MODIS is closer to CALIPSO. The maximum frequency appears near $0.2 \mathrm{~km}$.

(3) The applicability of the correction method is studied for different cloud top heights and optical thickness. The results shows the correction method is all effective. The lower cloud top height, the better correction. The thinner cloud optical thickness, the better correction.

Taking full advantage of active and passive remote sensing, the correction method for cirrus cloud top height of MODIS was proposed and the related performance was evaluated in this study. CALIPSO data was acquired from nadir pixels to match MODIS data. Observational geometry is not taken into account. It will be done in the future to solve non nadir pixels correction. The correction method of clouds with different spatial and temporal properties will also be researched further.

\section{ACKNOWLEDGEMENTS (OPTIONAL)}

This research was supported by the National Natural Science Foundation of China (61531019).

\section{REFERENCES}

Barnes, W. L., Xiong, X., Salomonson, V. V., 2003. Status of Terra MODIS and Aqua MODIS. Adv. Space Res., 32(11), 2099-2106.

Cao, Y. N., Wei, H. L., Chen, X. H., et al., 2012. Simulations of the reflectance of cirrus clouds in shortwave spectral region. Acta Optica Sinica (in Chinese), 32(8), 19-25.

Cao, Y. N., Wei, H. L., Dai, C. M., et al., 2015. Retrieval of the optical thickness and cloud top height of cirrus clouds based on airs high spectral resolution data. Spectroscopy and Spectral Analysis (in Chinese), 35(5), 1208-1213.

Cho, H. M., Yang, P., Kattawar, G. W., et al., 2008. Depolarization ratio and attenuated backscatter for nine cloud types: Analyses based on collocated CALIPSO lidar and MODIS measurements. Optics Express, 16(6), 3931-3948.

Hagihara, Y., Okamoto, H., Luo, Z. J., 2014. Joint analysis of cloud top heights from CloudSat and CALIPSO: New insights 
into cloud top microphysics. J. Geophys. Res. Atmos., 119(7), 4087-4106.

Haladay, T., Stephens, G., 2009. Characteristics of tropical thin cirrus clouds deduced from joint CloudSat and CALIPSO observations. J. Geophys. Res. Atmos., 114(D8), DOI: 10.1029/2008JD010675.

Heidinger, A. K., Pavolonis, M. J., Holz, R. E., et al., 2010. Using CALIPSO to explore the sensitivity to cirrus height in the infrared observations from NPOESS/VIIRS and GOES-R/ABI. J. Geophys. Res. Atmos., 115(D12), DOI: 10.1029/2009JD012152.

Holz, R. E., Ackerman, S. A., Nagle, F. W., et al., 2008. Global Moderate Resolution Imaging Spectroradiometer (MODIS) cloud detection and height evaluation using CALIOP. $J$. Geophys. Res. Atmos., 113(D8), DOI: 10.1029/2008JD009837.

Hu, S. Z., Ma, S. Q., Tao, F., et al., 2012. Ground-based dualband cloud observing system and its comparative experiments. Journal of Applied Meteorological Science (in Chinese), 23(4), 441-450.

King, M. D., 1987. Determination of the scaled optical thickness of clouds from reflected solar radiation measurements. J. Atmos. Sci., 44(13), 1734-1751.

Liou, K. N., 1986. Influence of cirrus on weather and climate process: A global perspective. Mon. Wea. Rev., 114, 1167-1199.

Liu, Z. Y., 2004. Use of probability distribution functions for discriminating between cloud and aerosol in lidar backscatter data. J. Geophys. Res., 109(D15):D15202, DOI: $10.1029 / 2004 \mathrm{jd} 004732$.

Lu, Y. J., Chen, G. Y., Gong, K. J., et al., 2012. Overview of researches on cloud sounding methods. Meteorological Science and Technology (in Chinese), 40(5), 689-697.

Marchant, B., Platnick, S., Meyer, K., et al., 2016. MODIS Collection 6 shortwave-derived cloud phase classification algorithm and comparisons with CALIOP. Atmos. Meas. Tech., 9, 1587-1599.

Meenu, S., Rajeev, K., Parameswaran, K., 2011. Regional and vertical distribution of semitransparent cirrus clouds over the tropical Indian region derived from CALIPSO data. J. Atmos. Sol. Terr. Phy., 73(13), 1967-1979.

Menzel, W. P., Frey, R. A., Baum, B. A., 2013. Cloud top properties and cloud phase algorithm theoretical basis document.

Nakajima, T., King, M. D., 1990. Determination of the optical thickness and effective particle radius of clouds from reflected solar radiation measurements. Part I: Theory. J. Atmos. Sci., 47(15), 1878-1893.

Nazaryan, H., Mccormick, M. P., Menzel, W. P., 2008. Global characterization of cirrus clouds using CALIPSO data. $J$. Geophys. Res. Atmos., 113(D16), DOI:10.1029/2007JD009481.

Rossow, W. B., Schiffer, R. A., 1999. Advances in understanding clouds from ISCCP. Bull. Amer. Meteor. Soc., 80(11), 2261-2287.

Sassen, K., Campbell, J. R., 2001. A mid-latitude cirrus cloud climatology from the facility for atmospheric remote sensing. Part I: Macrophysical and Synoptic Properties. J. Atmos. Sci., 58(58), 481-496.

Thorsen, T. J., Fu, Q., Comstock, J., 2011. Comparison of the CALIPSO satellite and ground-based observations of cirrus clouds at the ARM TWP sites. J. Geophys. Res. Atmos., 116(D21), DOI: 10.1029/2011JD015970.

Vaughan, M. A., Young, S. A., Winker, D. M., et al., 2004. Fully automated analysis of space-based lidar data: An overview of the CALIPSO retrieval algorithms and data products. Proceedings of SPIE - The International Society for Optical Engineering, 5575.

Wang, Z., Wang, Z. H., Cao, X. Z., 2016. Consistency analysis for cloud vertical structure derived from millimeter cloud radar and radiosonde profiles. Acta Meteorologica Sinica (in Chinese), 74(5), 815-826.

Wang, Z., Sassen, K., 2002. Cirrus cloud microphysical property retrieval using Lidar and Radar measurements part I algorithm description and comparison with in situ data. J. App. Meteor., 41, 218-229.

Weisz, E., Li, J., Menzel, W. P., et al., 2007. Comparison of AIRS, MODIS, CloudSat and CALIPSO cloud top height retrievals. Geophys. Res. Lett., 34(17), 251-270.

Winker, D. M., Vaughan, M. A., Omar, A., et al., 2009. Overview of the CALIPSO mission and CALIOP data processing algorithms. J. Atmos. Ocean Tech., 26(11), 23102323.

Yang, B. Y., Zhang, H., Peng, J., et al., 2014. Analysis on global distribution characteristics of cloud microphysical and optical properties based on the CloudSat data. Plateau Meteorology (in Chinese), 33(4), 1105-1118.

Yang, B. Y., Wu, X. J., Guo, Z., 2017. The characteristics of cloud properties in deep convective clouds across China with the CloudSat dataset. Plateau Meteorology (in Chinese), 36(6), 1655-1664. 
Yang, B. Y., Wu, X. J., Wang, X., 2019. The sea-land characteristics of deep convections and convective overshootings over China sea and surrounding areas based on the CloudSat and FY-2E datasets. Acta Meteorologica Sinica (in Chinese), 77(2), 256-267.

Zhang, H., Yang, B. Y., Peng, J., et al., 2015. The characteristics of cloud microphysical properties in East Asia with the CloudSat dataset. Chinese Journal of Atmospheric Sciences (in Chinese), 39(2), 235-248.

Zhang, X. Y., Hu, H. B., 2017. Spatio-temporal characteristics of aerosol optical depth and their relationship with urbanization over Beijing-Tianjin-Hebei region. Chinese Journal of Atmospheric Sciences (in Chinese), 41(4), 797-810.

Zhou, F. F., Zhou, M. Q., Wang, J., et al., 2010. Relationship of cloud-top heights retrieved from combination of FY-2C/D geostationary satellite data and other observation data and radar-retrieved echo tops. Meteorological Monthly (in Chinese), 36(4), 43-50. 